\title{
Status of e-Science Activities in Mongolia
}

\section{Nergui B. ${ }^{1}$}

Institute of Informatics of Mongolian Academy of Sciences

Enkhtaivan ave. 54b Ulaanbaatar 51, Mongolia

E-mail: abnerguiearvis.ac.mn

\section{Bulgan G.}

Institute of Informatics of Mongolian Academy of Sciences

Enkhtaivan ave. 54b Ulaanbaatar 51, Mongolia

E-mail: bg_329@yahoo.com

This report covers :

- Current ICT development in Mongolia and the status of Mongolian information technology,

- Current information technology situation in the Mongolian Academy of Sciences,

- Collabration between the Taiwan Academy of Science, Russian Research Institutes in grid systems,

- Objectives and requirements of developing e-science in Mongolia.

The International Symposium on Grids and Clouds (ISGC) 2012

Academia Sinica, Taipei, Taiwan

February 26-March 2, 201

1 Speaker 


\section{Introduction}

Mongolia has an extensive plateau with an average height of 3000 meters above the sea level and 1566500 sq.km of territory. Nearly half of the population lives in the capital city, Ulaanbaatar, the capital and administratively, Mongolia is divided into 21 aimags (provinces).

\section{THE ICT DEVELOPMENT OF MONGOLIA}

The ICT development of Mongolia has advanced tremendously over the last five years. The Telecommunications network of over thirteen thousand km's of fiber optic cable covers all of Ulaanbaatar, the capital city of Mongolia, and connects all aimag centers and some 151 soum centers. The number of mobile phone subscribers has reached over 2.3 millions. The Internet is widely used in all sectors of economic and social development of Mongolia.

\section{Internet backbone connection}

Currently 3 main operators provide wholesale internet connection services

- Railcom (Subsidiary of Mongolian Railway)

- Gemnet

- Mobicom

- Mongolian Internet Exchange (MIX)

- Uses Cisco Nessus Switch

- Runs BGP for peering

- Connection interfaces are $1 \mathrm{G}, 10 \mathrm{G}$ ethernet

- Total outside connection bandwidth is $12 \mathrm{Gbps}$

\section{Internet backbone connection}

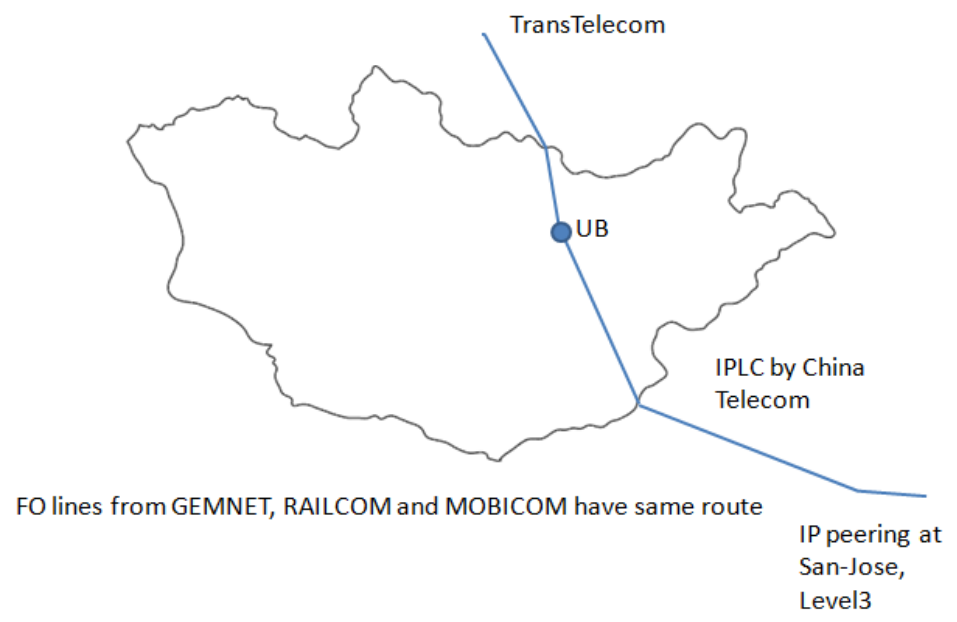

Figure.1 Internet backbone connection 


\section{CURRENT ICT DEVELOPMENTS IN THE MONGOLIAN ACADEMY OF SCIENCES}

In Mongolia research activities are being carried out at different universities and various institutes of the Mongolian Academia of Sciences (MAS). The MAS has 22 research institutes and centers which are located in 6 different places within up to $17 \mathrm{~km}$. Institute of Informatics has been providing Internet service of the MAS since 1996. Over 600 computers are connected to the current local network (speed of $15 \mathrm{Mbps}$, Fiber backbone).

Unlike different universities in Mongolia, the institutes and centers of the MAS have much information about history, archaeology, paleontology, geography, botany, biology, natural resources, language and literature of Mongolia which has been collected due to the research activities and field investigation performed for many years. In order to have a public access to this information, it is vitally important to create an integrated computerized database and disseminate the information via the Internet and electron publishing.

For example:

- There are about 10,000 scientific base documents,

- catalog including description of 7,800 species of insects,

- catalog of habitat description of 9,000 insects,

- 4,000 stuff models of 4,000 birds.

- Mongolian state fund and private herbarium collections possess 75,000 perennial, 3,500 vegetation species of swamp areas, 10,000 weed plants, 10,000 moss plants and 2,500 fungus species.

- $\sim 600$ traditional songs and other folklore, $~ 300$ art works, 20 sculptures and more than 40 kinds of instruments.

\section{Example research studies include:}

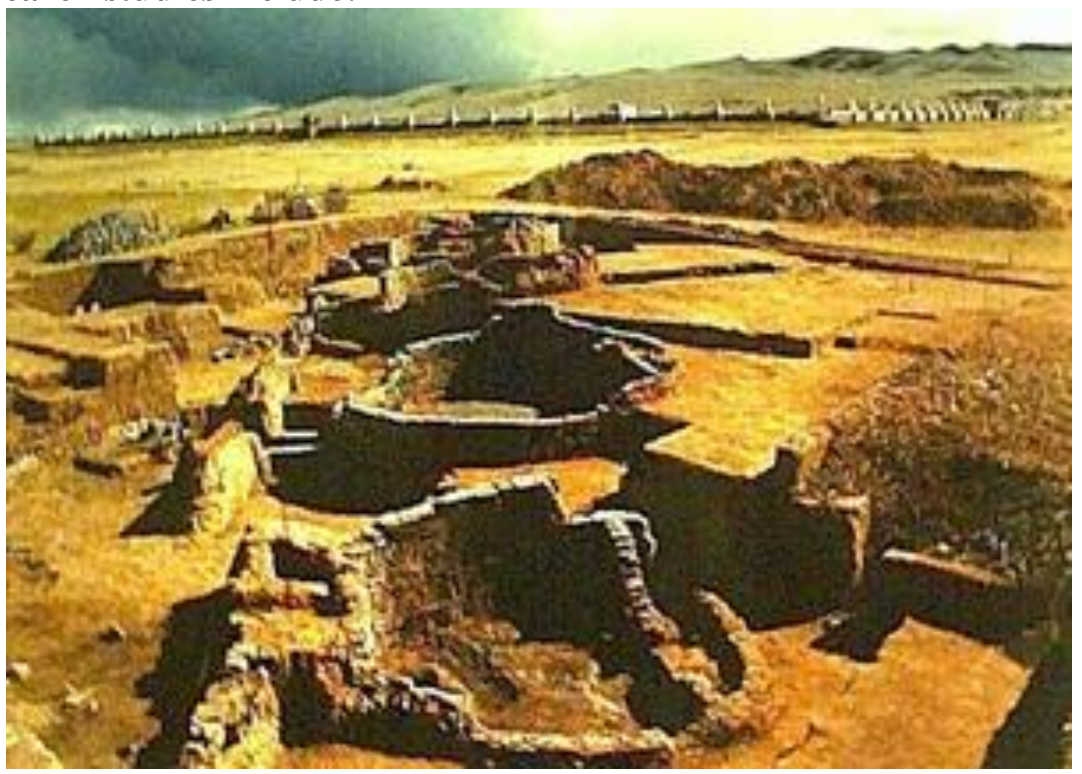

Figure.2 Archaeological investigation of ancient capital of Mongolian Empire Khara-Khorum. 


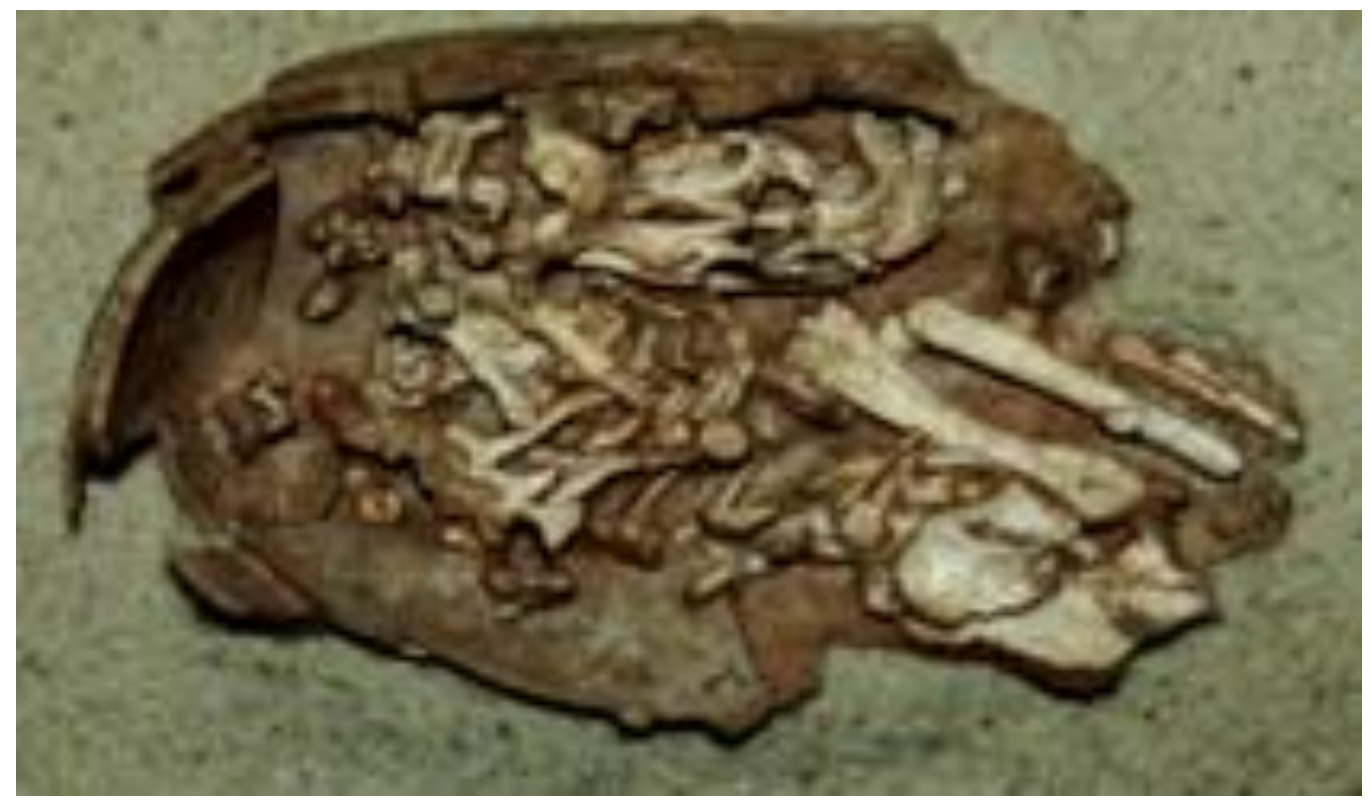

Figure.3 The Oviratorid embryo from Ukhaa Tolgod, Mongolia, in the Gobi desert is the first definitive embryo of nonavian theropod dinosaur. This embryonic skelet on of a nonavian theropod dinasour was found preserved in an egg from Upper Cretaceous rocks in the Gobi desert of Mongolia in 1993. The egg containing the embryo is incomplete, but the preserved portion is similar to oblong eggsclassified as elongatodithid.

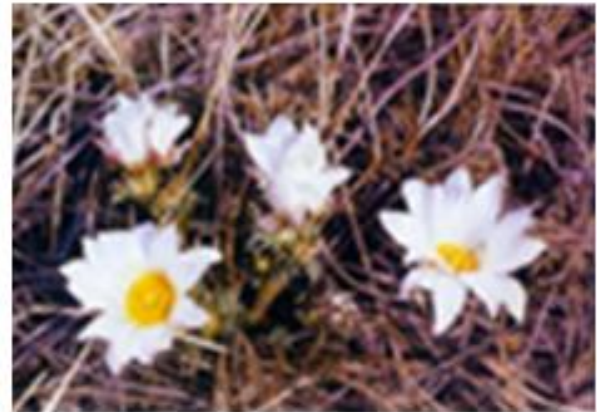

1. Adonis mongolica Sim.

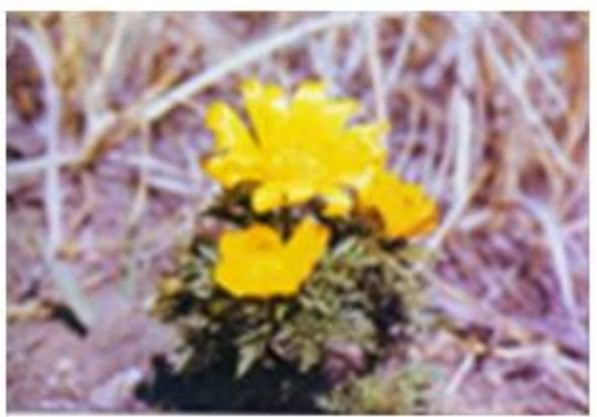

2. Adonis sibirica Patr. ex Ldb.

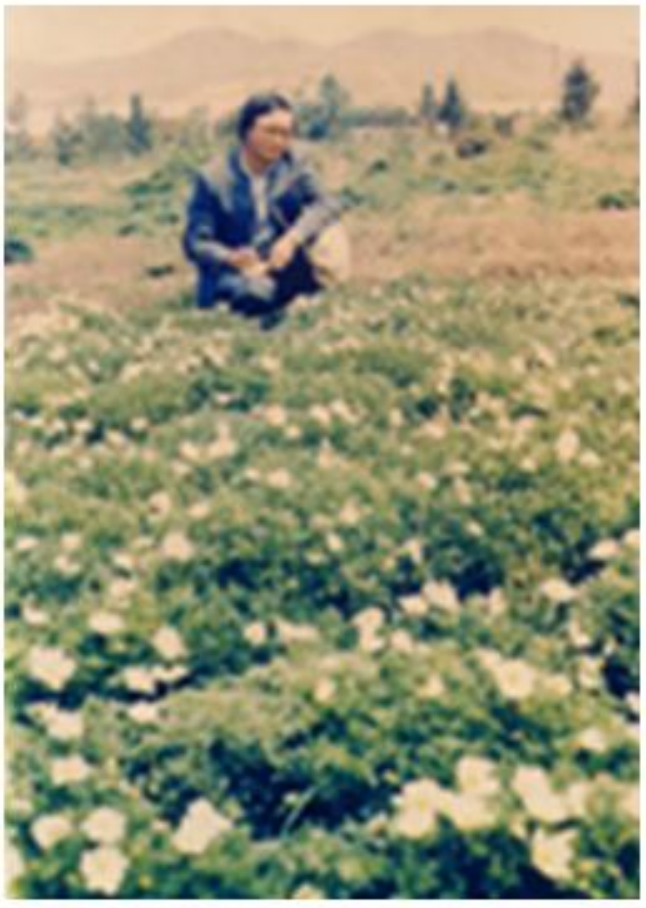

3. View of Adonic mongolica Sim cultivated plantation.

Figure.4 Some archives from botany. 

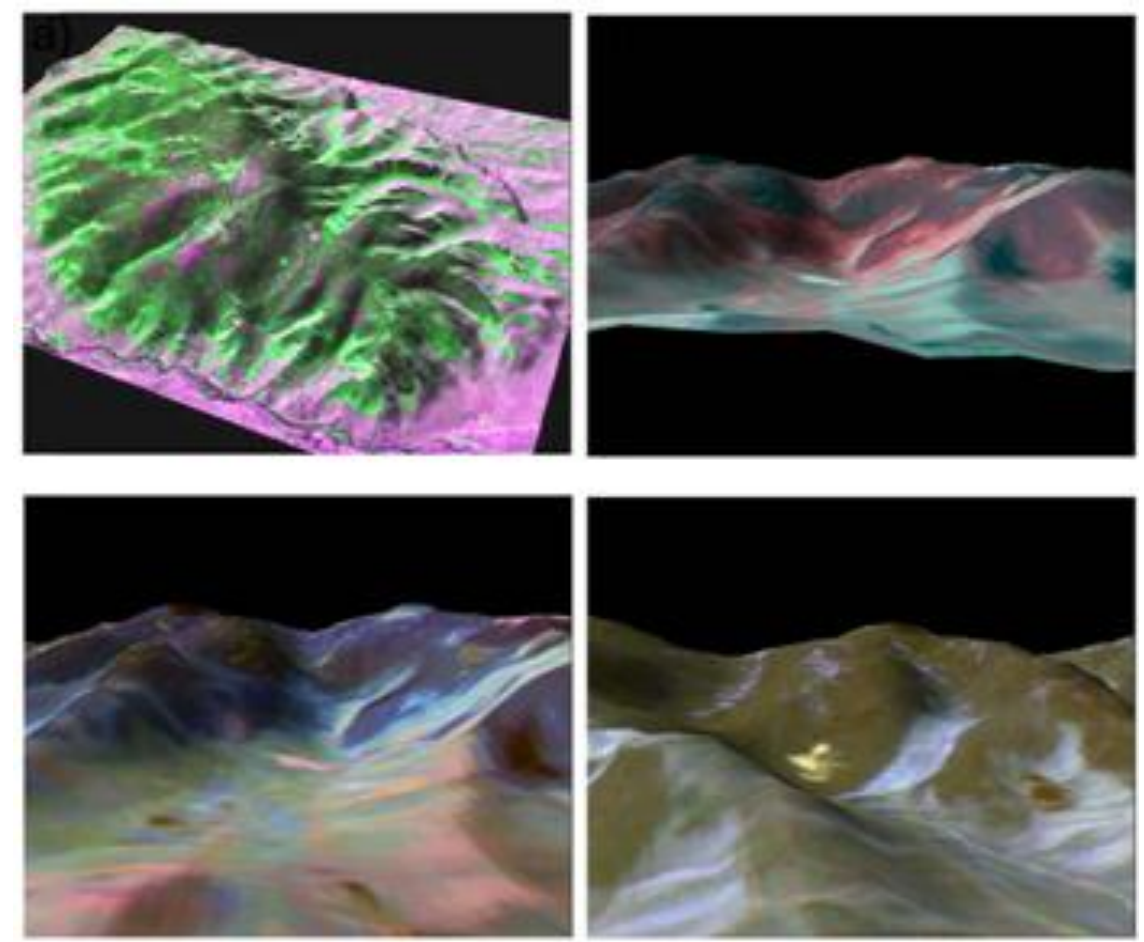

Figure.5 Examples some terrain image analyzing results.

\section{GRID COMPUTING}

The Consortium "Mongolian Grid" was founded under the aegis of Mongolia's Nuclear Energy Agency whose members are the following organizations:

- The Institute of Informatics of the Mongolian Academy of Sciences Mongolia

- The School of Mathematics and Computer Science of the National University of

- The Institute of Telecommunications and Information Technology of the Mongolian University of Science and technology.

\subsection{GRID SYSTEM PROJECT WITH INTERNATIONAL COOPERATION}

\section{Grid System Project Cooperating with Taiwan Academy of Science}

The Mongolian Academy of Sciences in cooperation with the Secretariat of the science Council of Asia completed the preparation for the Conference and the "11 ${ }^{\text {th }}$ Science Council of Asia (SCA) Conference" was successfully held on 4-6 July 2011 in Ulaanbaatar. At the request of the Mongolian Academy of Sciences Dr. Simon C. Lin organized the section of the conference "Developing e-Science in Asia". During the conference "Memorandum of Understanding for Research Cooperation between e-Science Working Group of Mongolian Academy of Sciences and Academia SINICA Grid Computing Centre” was signed.

The results of this memorandum have been rapidly shown. For instance, "Workshop on e-Science Application and Technology" was organized on 3-5 October 2011 on Dr. Lin's initiative. That workshop attracted the attention of the Mongolian Academy institutes, universities, and scholars as well as ISP-operator companies. Over 90 people participated in the training. 
The three people from Mongolian Academy of Sciences are participated in the following Conference and Symposium.

- TELDAP International Conference 2012

- The International Symposium on Grids and Clouds (ISGC 2012)

\section{$\underline{\text { Other activities }}$}

- In 2011 the Institute of Informatics become organizational member of the Pacific Neighborhood Consortium. The two people from the Mongolian Academy of Sciences are participated in the "Pacific Neighborhood Consortium (PNC) Annual Conference and Joint Meetings" which was helded in Bangkok, Thailand from October 19 to 21, 2011.

- The Mongolian Academy of Sciences as a member of the International Council for Science (ICSU) sent its delegates to the Conference "Data-Intensive Science and Discovery - CODATA 45 years on" held on October 30, 2011, Beijing, China and expressed its willingness to become a member of this organization.

- The Mongolian side organized successfully the "Workshop on Open Knowledge and Data Environment for Innovative Research, Education and Society (OKDE) in Asia" of the International Counsil for Science on 4-6 July 2011 in Ulaanbaatar.

\subsection{RESEARCH COOPERATION WITH RUSSIAN RESEARCH INSTITUTES}

\section{$\underline{\text { International Joint Institute for Nuclear Research in Dubna, Russia }}$}

Currently we are working on educational GRID system in cooperation with the Information Technology Laboratory of the Joint Institute for Nuclear Research in Dubna, Russia.

- Two teachers from the National University of Mongolia and the Mongolian University of Science and Technology are being trained here as educational GRID system administers based on gLite 3.2 service.

- Our six students will participate in the 2012 summer school here too.

\section{Irkutsk Centre of Siberian Branch of the Russian Academy of Sciences}

- The 3 year joint project on "Establishment of an Integrated Information and Telecommunication Network of Mongolia's Research Institutions" is underway in cooperation with Irkutsk Centre of Siberian Branch of the Russian Academy of Sciences last year.

- The project is aimed at the solution of an actual task - creation of an integrated information and telecommunication infrastructure to support interdisciplinary research at the institutes and centres of the Mongolian Academy of Sciences (MAS) as well as to enhance openness and access to scientific information resources of the Mongolian Academy of Sciences for the world community. 
- This project is financed by 70:30 ratio (the Irkutsk Center - 70 percent and the Mongolian Academy of Sciences - 30 percent).

- It is planned to lease a high speed channel of communication to link the Irkutsk Center with the Institute of Informatics in 2012. The Irkutsk Center will cover fully the lease.

- Metadata is being inserted into the information resources of the institutes of the Mongolian Academy of Sciences as well as testing and configuration of the comprehensive/extensive catalogue.

- In doing so modern international standards of metadata like Dublin Core, FGDC-STD001-1998, ISO 19115/19119/19110 are being used for description of information resources.

\section{OBJECTIVES AND REQUIREMENTS OF DEVELOPING E-SCIENCE IN} MONGOLIA

In recent years, research into nano-technology, biotechnology and producing natural medicine is developing rapidly in Mongolian universities and science institutes. Mongolian physicists are successfully participating in LHC research collaboration. Mongolia is located in an active seismic zone of central Asia.

Thus, in Mongolia, using Cloud Computing is needed urgently. Mongolian low economic status and insufficient number of well trained professionals are requiring us to participate in international research projects.

\section{References}

[1] White paper on Information and Communications Technology Development of Mongolia-2010, 